\title{
LA LOGICA «SMITHEANA» EN LA HISTORIA ECONOMICA Y SOCIAL DE MADRID. A PROPOSITO DE UNA TRADUCCION RECIENTE
}

\author{
SANTOS MADRAZO MADRAZO
}

Equipo Madrid. Universidad Autónoma de Madrid

Confieso la desazón que me produce esa especie de determinismo ecológico que habla de un dinamismo urbano y de una pasividad rural, de acuerdo con la lógica «smitheana» de suponer que la esfera comercial —en virtud de la lógica de un progreso natural y poco conflictivo- fue la causa del incremento de la productividad, del desarrollo agrario y de los cambios demográficos, institucionales o de conducta. Este canto al deus ex machina del intercambio ignora que la fragmentación de la soberanía feudal compatibiliza la existencia de una economía rural y de una economía urbana. Es más, si se despieza la realidad serían los campesinos quienes transformarían la renta feudal, estimulando con ello la producción independiente de mercancías, tal como sugiere J. Merrington y E. Sereni, en un recorrido que arranca de Marx y pasa por M. Dobb '.

No considero oportuno acumular citas para pormenorizar esta línea argumental, pero desearía convencer de la necesidad de analizar las ciudades como focos concentradores de la riqueza de la tierra y como espacios de poder social, pues es ahí, en la «externalidad interna» de la ciudad respecto al sistema feudal, donde radican los cambios económicos y sociales. Ello no supone restar interés a la esfera urbana, ni silenciar las diferencias campo-ciudad, sino estudiarlas a partir de la persistencia de un modelo feudal de control social. A partir de esto - tan feudal es la economía urbana como la economía rural- es como debe entenderse la vinculación y posible desarticulación del interior castellano por la capital. La Monarquía estaba mimando a su Madrid con una parte importante de la renta feudal estatal, mientras el resto del sociales urbanas no respondieran a aquellas coerciones. Este es el marco que, en definitiva, sella y fija la proyección y los limites de la ciudad.

Lo anterior viene a cuento de que ha vuelto a retonar un viejo artículo

' Merrington (1977) y Sereni (1980). 
cuando ya se creía agostada su capacidad explicativa ${ }^{2}$. Su autor debió dudar de la importance de su simple model cuando se pasó de lleno a la demografía y no ha vuelto a verificar su concepto de economía dual, la rural y la urbana. De acuerdo con ello, los flujos de la capital hacia el resto del país se medirían por este decálogo de implicaciones:

- capacidad para crear un mercado nacional;

- introducción de cambios agrarios;

- variaciones en el suministro de materias primas;

- mejora en las facilidades comerciales;

- perfeccionamiento del transporte;

- elevación de los salarios reales;

- adecuación de las condiciones demográficas;

- primacía de lo racional sobre lo tradicional;

- logro de nuevas formas de movilidad social;

- introducción de nuevos hábitos de consumo.

En el caso de Londres, la interrelación de tales vínculos actuaría como disolvente del país, auspiciando cambios que desembocarían en la Revolución Industrial. Es la lógica de Adam Smith, secundada por unas gentes que verán natural cualquier cosa que venga rebozada por el progreso de una economía libre.

El negativo de este modelo ha sido recientemente aplicado por David $R$. Ringrose ${ }^{3}$ para un Madrid que no sólo fue incapaz de minar la estructura de la sociedad tradicional, sino que contribuyó a «desestructurar» el interior castellano. Tal especie de contramodelo está bien traído y su desarrollo se basa en hipótesis sucesivas e interrogantes con apoyatura teórica. Pero estas reflexiones en su haber constituyen sólo una parte, que requiere de los hechos para ser un discurso histórico completo. Tal petición no es un simple reclamo positivista, sino el elemental empirismo para una negociación correcta (E. P. Thompson). Es por aquí, también, por donde flojea este estudio, ya que las hipótesis y las buenas ideas requieren una base informativa necesaria. Por supuesto que puede escribirse un mal libro con muchos datos y otro bueno con escasa información, pero en este último caso que se diga abiertamente por qué se omiten unas fuentes mientras otras son buscadas con premeditación. Creo que este tipo de confesiones legitima nuestra disciplina y nuestro quehacer de historiadores.

Practicando esta claridad que predico: si la aportación de Ringrose estu-

${ }^{2}$ Wrigley (1967).

${ }^{3}$ Ringrose (1985). 
viera mal hecha no sería peligrosa por la sencilla razón de que las chapuzas, tarde o temprano, obturan su propia divulgación. Por el contrario, el que esta obra cuente con recursos y pasajes brillantes puede incrementar su influencia en la historia económica y social madrileña. Si, además, muestra las relaciones de Madrid con la periferia peninsular y está montada sobre cuatro siglos distintos, el interés gana en globalidad y perspectiva.

La importancia de la obra se agranda al cubrir un vacío. En efecto, el listón de la historiografía madrileña apenas ha remontado el nivel en que la dejaron sus cronistas y eruditos locales. Si se repasan sus órganos de difusión topamos con que de los 200 autores, que han colaborado con 500 artículos en los 21 números de la revista Anales del Instituto de Estudios Madrileños, no aparecen colaboraciones que superen lo que se entiende por un subproducto. Es más, puede afirmarse que vamos de mal en peor, pues en el otro órgano - Revista de la Biblioteca, Archivo y Museo del Ayuntamiento de Madrid - los trabajos históricos de su primera época (1924-1936) son de mejor calidad que los publicados desde 1977. Multitud de estudios, por tanto, en los que prima lo sectorial y erudito, y escasez de investigaciones globales.

Al revés que Barcelona o Segovia, por ejemplo, Madrid todavía no ha alcanzado esos mínimos que permitan calar en los fundamentos históricos de su estructura regional y urbana. Por eso mismo, libros como el de Ringrose animan y son de agradecer para los estudiosos de temas madrileños y de la historia económica general. Tampoco esto extraña a quienes hemos seguido los pasos de este historiador estadounidense, que desde hace veinte años viene trabajando en la historia económica de España, y ya nos ha proporcionado otro libro sobre transporte, amén de una docena de artículos. Ahora bien, no creo que se necesiten casi 500 páginas para desarrollar una aportación cuando lo principal de ella ya nos la había contado en otros trabajos.

$Y$ paso ya, de una vez, a seleccionar media docena de aspectos, causantes de que el citado modelo y sus valores tendenciales no coincidan con la realidad.

A) Las averiguaciones de alcabalas como indicadores de la actividad económica encierran un alto valor explicativa. Podrá discutirse su manejo de cara a los arrendamientos, encabezamientos o a la heterogeneidad de productos que cubre, pero su utilidad es irrefutable ${ }^{4}$. No me explico cómo se ha

4 La aplicación de tales rentas al estudio de la producción y transacciones tampoco es nueva, pues ya fue recogida por Ramón Carande, to ha sido por José Ignacio Fortea y lo está siendo por Jaume Torras. 
podido dar la espalda a esta documentación, imprescindible para interpretar correctamente las entradas y salidas de mercancías de Madrid.

B) ¡Lamentarse por falta de información, anterior a 1800, en el abasto de grano! Los lamentos pueden venir por lo contrario. En los Archivos de Simancas, Histórico Nacional y Villa de Madrid se conservan series para reconstruir hasta el último mendrugo de pan consumido en la Corte. Es precisamente la ausencia de este material central lo que le lleva a estimaciones del consumo anual con diferencias de 200.000 y 300.000 fanegas en breves lapsos de tiempo. Los pocos datos no le impiden, sin embargo, afirmar que hacia 1630 el «consumo normal» de Madrid se acercaba a las 700.000 fanegas, y lo refleja en un gráfico (p. 138) en el que el autor ha querido - no los hechos- hacer coincidir población y consumo. No menos duro resulta creer que el suministro de trigo a Madrid fue mayor en 1630 que en 1847, cuando en esta última fecha había 50.000 bocas más. Podía pensarse que en 1847 hubo escaseces, pero eso ocurrió con mayor intensidad en 1630, año precedido de cuatro malas cosechas y de una elevación de precios cuyo promedio no fue superado en la primera mitad del siglo xvir.

Menos mal que para el vino no establece la correlación entre población y consumo, porque, de haberlo hecho, los habitantes de 1627 se hubieran multiplicado por cuatro dos siglos después. Sería deseable una explicación de por qué el consumo de, por ejemplo, 1597 era 0,567 litros de vino por persona y día. Atención, porque si se descuentan los niños menores de diez años y alguna monja abstemia, quedarían miles de madrileños que superarían la dosis del litro diario. Tener a la población agarrada a la frasca no creo que fuera un método de gobierno, pero facilitaría a Velázquez encontrar modelos - si se estaban quietos- que posaran para su famoso cuadro.

El año 1630... Para el consumo de carne ofrece tres muestras de unas pocas semanas en todo el xvir. No le basta con extrapolarlas, sino que la cifra de 1630 la eleva, porque él quiere, en 1.290 .000 libras sobre la estimación extrapolada. No entro en bailes de cantidades ni en la ausencia de otros ramos del consumo, pues el abasto madrileño abarcaba más de cinco productos, además de los indirectos.

En la participación del Pósito en el consumo madrileño, y en cuanto se refiere a la geografía y organización de la demanda capitalina ${ }^{5}$, sólo hay esbozos, y así lo reflejan los pocos datos y los años sueltos que han servido para la confección de los mapas. Sin que éstos sean razonablemente rellenados, no entiendo que pueda revisarse el concepto de mercado nacional aplicado por Josep Fontana.

\footnotetext{
'De Castro (1984) y Bernardos (1985).
} 
C) Sin una base informativa, las extrapolaciones resultan peligrosas, mientras los valores tendenciales pueden conducir a deformaciones en la demografía, en el volumen y dirección del tráfico o en la naturaleza de los flujos entre el interior y la periferia. Esto se palpa nada más abrir el libro. A Ringrose le han gustado los ingresos procedentes del peso mayor $y$ correduría de Madrid, así como los de la barca de Arganda. Por eso ha reproducido sus series - siempre sin citar la fuente- en diferentes publicaciones, lo cual no elimina su aleatoriedad.

De haber consultado las cuentas del mayordomo de Propios de Madrid y los cientos de expedientes que se conservan sobre estas rentas - también de la barca de Arrebatacardos y del pontazgo de Viveros- hubiera encontrado: a) que hay irregularidades en las tasas impositivas a lo largo de los 259 años de las series; b) que existen múltiples variaciones temporales en los contratos de arrendamiento e incluso el Consejo de Castilla condona cantidades; c) que no hay homogeneidad en las numerosas exenciones y evasiones; d) que los ingresos, aparte de ser deflactados, dependen de la ruta seguida por el usuario, y por la barca de Arganda pasaba uno de los trazados que desde Levante coludían en Madrid; $e$ ) que la recaudación estaba en relación con los vados, con optar entre una barca de dos o cuatro remeros y con algo muy común: la arbitrariedad exactiva; $f$ ) que los ingresos podían depender -y a veces así se dice- más del tráfico de áridos para las construcciones madrileños que del comercio con Levante.

De tenerse en cuenta estos aspectos, las curvas de ingresos y población se hubieran mordido y hubieran variado las conclusiones sobre la relación del auge y decadencia de la capital con el interior, con la periferia y con el mundo exterior. Veamos: los ingresos del peso mayor son más elevados en 1591 1610 que en 1621-1640; los de 1751-1760 menos de la mitad que los de $1761-1770$, y éstos más que duplican los de 1630 , cuando la población era 25.000-30.000 habitantes menor. Basta este cotejo para ver que el índice de capacidad de consumo madrileño de productos del interior no casa con la evolución demográfica. Por otra parte, si el barcaje rindió más en la segunda mitad del XVII que en la primera, la conclusión es evidente: tales ingresos no se hacen eco del modelo de las regiones costeras, ni de la demanda cualificada de las élites madrileñas ni de la distribución de la renta propuesta.

Por mucho que se juegue con ponderaciones relativas - secuela de una información fragmentaria - la estructura y evolución del mercado urbano madrileño se resienten a pesar de los esfuerzos por marcar contracciones y recuperaciones. Así: no pueden sacarse conclusiones para el período 1789-1847, basadas en poco más que las dos series de esos dos años, pues esto deja en paños menores a cualquiera. Un ejemplo: al asegurar que Madrid importaba 
un 6 por 100 menos de cueros y un 22 por 100 menos de pieles en 1847 que en 1789 , concluye que la industria urbana se había contraído y, «en consecuencia, también el consumo de materias primas que la capital adquiría en la España interior». Pues bien, ocurrió justo al revés, ya que si hubiera leído bien el Diccionario de Madoz — de donde ha tomado los datos- vería que Madrid importó en 1847 un volumen de pieles siete veces superior al de 1789 y todavía más veces de cueros y curtidos. Si utilizáramos su línea argumental cabría concluir que no hubo contracción, etc...

Con las entradas de trigo ocurre lo mismo: no se puede jugar con la cantidad del año 1789 -773.639 fanegas — y compararla sin más con las 541.885 fanegas de 1847, porque las consecuencias serán distorsionantes para su idea del estancamiento madrileño y su influencia en el interior. ¿Por qué no ha tomado las 955.258 fanegas del año siguiente (1848) o las de todos los años comprendidos entre 1789 y 1847 , ya que existen? No entiendo por qué un investigador se ha de servir de antologías cuando tiene a mano obras completas.

Estas son algunas secuelas del sugestivo modelo de Wrigley al hacer de la actividad comercial - y del crecimiento capitalista - el disolvente pacífico y racional de todo tipo de problemas y no tener en cuenta suficientemente la producción-relaciones sociales ni tampoco lo político.

D) Sabido es lo peligroso que resulta utilizar los ingresos impositivos para calcular cifras de consumo. ¡Pues imagínense para estimar la población! El resultado a fortiori ha de ser no menos distorsionante.

Ringrose ha publicado sus estimaciones de la población de Madrid en numerosas ocasiones. Puede hacerlo muchas más, pero no convencerá mientras no presente otras pruebas que las aleatorias de consumo y rentas que acabo de citar. Cuando introduce otras nuevas - los bautismos- se vuelven contra él. En su arropamiento a los 175.000 habitantes de 1630 alega que los bautismos del quinquenio $1622-1626$ fueron 4.164 por año, mientras en la déca$\mathrm{da}$ de 1750 , con 35.000 habitantes menos, los bautizados fueron 4.750 , y eǹ el quinquenio 1803-1807, cuando la capital estaba menguando, la media fue de 4.949. Averiguar por qué en estos dos últimos períodos se bautizan 586785 personas más que en el primero obliga al recurso de la inmigración, ya que en Madrid, como en Londres y otras ciudades preindustriales, la tasa bruta de mortalidad fue más alta que la de natalidad. Por tanto, a los 4.583 habitantes, promedio del crecimiento anual de Madrid entre 1606 y 1630, debe sumarse el porcentaje de la caída de la natalidad, lo que significa que en 24 años llegaron a Madrid 154.011 inmigrantes. Y de esto, al revés que para 1850 , no sabíamos gran cosa ${ }^{6}$, por lo que continuaremos aceptando los

\footnotetext{
- Carbajo (1985).
} 
aproximadamente 130.000 habitantes de que habla Domínguez Ortiz para 1619 y para $1659^{7}$.

Insisto en la inmigración. Este es un tema de alto interés para la historia urbana, pero siempre que se hable - cosa que Ringrose no ha hecho- de las direcciones y efectos de los inmigrantes en relación con su origen, carácter y conexiones políticas y religiosas, o en su adaptación a las demandas económicas y sociales de la capital.

Insisto en la población. Basta una simple operación aritmética para darse cuenta que los habitantes de Madrid durante el Antiguo Régimen representan un escaso porcentaje respecto a la población total española. Nada, por tanto, que permita hablar de un país padeciendo una prematura macrocefalia. Lo que pasa es que Ringrose no supera el clisé actual de un Buenos Aires madrileño en una Argentina española.

E) Madrid importaba en 1789 por valor de 433 millones de reales, mientras sus exportaciones sólo ascendían a 6,5. La renta madrileña no llegaba ni con mucho a aquella cantidad. Luego de alguna parte salía la diferencia. Se ha dicho siempre que la Corona era generosa con la capital..., que ahí estaba la Corte..., y el Gobierno... y mucha burocracia... No hay duda que esto era cierto; pero requiere una explicación que pase por la relación entre clases y fracciones de clases ${ }^{8}$. Y es que no puede hablarse de rigidez en la división de clases y luego dar a entender que la clase es una categoría residual.

Ringrose habla de un núcleo urbano rico y de una corteza suburbana pobre ${ }^{9}$. La segunda diferenciación distingue la estructura social, pero los datos sueltos del xvir, los del Catastro de Ensenada, recogidos por Antonio Matilla, y los del Censo de Floridablanca, sólo le ofrecen respuestas plagadas de irregularidades. Lo fiable, lo ilustrativo ha de venir de un análisis de las rentas inmobiliariäs urbanas; de los gremios; de la familia; de la delincuencia; de las oligarquías; de la hacienda, fiscalidad y niveles de renta; de las transferencias nobiliarias, eclesiásticas..., y de otros aspectos que está estudiando el Equipo Madrid del Departamento de Historia Moderna de la Universidad Autónoma. Si hablamos de ciudad sanguijuela, de capital parásita o de binterland arruinado por los tentáculos de la Corte, además de abocar a un dualismo urbano y señorial - dos caras de una misma cosa- estaremos olvidando que la Monarquía, adonde iba a parar, por ejemplo, más de la mitad de los ingresos de la hacienda local madrileña, también aplastaba a muchos ma-

T Carbajo (1984). En espera de su pronta publicación en Ed. Siglo XXI.

- Bahamonde y Toro (1978).

- Aquí el modelo es de Hibbert (1953). 
drileños ${ }^{10}$. $\mathrm{Y}$, por supuesto, no todo Madrid era «inmune a las dificultades económicas».

Tampoco las gentes de otras ciudades estaban vacunadas contra esas dificultades. Creo, por lo demás, que una ciudad se diferencia de otra más por la organización social que por su proximidad o lejanía del mar, aunque esto último no sea desdeñable y pueda influir poderosamente en la acumulación.

Ringrose, que alguna vez se ha mostrado simpatizante de los modelos contrafactules, podría habernos presentado la situación de la Castilla interior en el supuesto alternativo de que Madrid no hubiera sido la capital y sí Toledo o Valladolid. Digo esto porque hubo núcleos urbanos sobre los que Madrid no ejerció influencia y también se desestructuraron a partir de 1600 , mientras otros lo hicieron antes de que Madrid desbancara a Toledo. Entre otras opciones, el autor ha preferido un periplo por varias ciudades españolas en busca de barras, pesos, almotacenías, corredurías, mollages, lleudas, aduanillas, barcas y blancas. La explicación de la desarticulación provocada por Madrid hubiera variado de indagar la producción, la apropiación de excedentes y otras motivaciones del restringido mercado interior, porque aquellas fuentes - por sí solas- no demuestran el porqué Madrid se hizo con las funciones y servicios urbanos del interior.

F) Una última apreciación sobre la historia urbana. Conocida es la renovación teórica que ha contribuido a su reactividad. Me parece válido, por ejemplo, el aporte de $M$. Foucault cuando habla de la ciudad como forma de poder y en la que se desarrollan las técnicas de control social con la finalidad de normalizarlo todo. Igualmente aprovechable es la aportación de F. Choay introduciendo la semiología urbana, exigente de una «gramática de los lugares» de trabajo, placer, soledad, violencia, deseo. El funcionalismo continúa siendo útil —sólo metodológicamente - al demandar una correlación entre los niveles o territorios de la historia urbana.

A estas y otras renovaciones cabe añadir los préstamos interdisciplinares -aunque se habla mucho y se practica poco- procedentes de la demografía, la sociologia, la arquitectura, la geografía o la economía urbana. En todo esto hay algo o mucho de válido: cambios interesantes que han beneficiado a la historia urbana, aunque no den la explicación global que requiere la disciplina.

La última interpretación o concepción «ecuménica» se debe a F. Braudel, quien ha deslumbrado con su teoría - por decir algo- de que la ciudad es siempre una ciudad, o que la ciudad es el destino del mundo, o que las ciudades son como transformadores eléctricos. Las palabras son distintas, pero el historiador francés está repitiendo aquello que de multifuncional tiene la

${ }^{10}$ Hernando (1985) y De la Hoz (1985). 
ciudad, y que ya expusiera L. Febvre, hace medio siglo, al indicar que es sobre las bases de la función cómo las ciudades pueden ser clasificadas. Ambos parecen empeñados en no explicar nada antes de meterse en un «entramado teórico». Y lo justifican diciendo que la ciudad es algo complejo...

Por suerte existen los que se han dejado «aprisionar» o «mutilar» por ese «entramado teórico». Y es precisamente M. Castells, profesor de la Universidad Autónoma de Madrid, quien declara y practica que no hay teoría del espacio que no sea parte integrante de la teoría social general. Habrá que continuar ahondando en las estructuras de poder, pues son ellas las que han engendrado el concepto de ciudad. Por ahí puede entrar aire fresco a la historia urbana y no por las tentaciones de comparar la ciudad a un organismo o a un transformador.

Lo anterior no lo he dicho sin intención, sino como alternativa a los que siguen hablando de determinismo ecológico de la economía dual y olvidan analizar las ciudades como espacios de control social. Ellos sabrán por qué atribuyen a los intercambios la clave de la «acumulación autorreproductiva». A Adam Smith también le gustaba hablar de un mercado propiciador de transformaciones y de una circulación de mercancías como motor del desarrollo histórico. Quienes no comulgamos con estas «leyes naturales» pedimos que se nos dejen contar las contradicciones surgidas de la ocupación del espacio por la clase dominante.

\section{BIBLIOGRAFIA}

BАн нмоNDE, A., y TORo, J. (1978): Burguesia, especulación y control social en el Ma-

BA HAM NDE, Aglo XIX, Madrid, Siglo XXI.
drid del siglo
BernaRDos, J. U. (1985): Las relaciones Madrid-Castilla la Vieja en el siglo XVIII. arrieros de Sangarcía (tesis de licenciatura), Unilla de Madrid, 1594-1840 (tesis doctoral), UniCarbajo, M.: (1984): La pobla
versidad Complutense.

- (1985): «La inmigración a Madrid (1600-1850)», Revista Española de Investigaciones Sociológicas, 32, pp. 67-100.

De Castro, C. (1984): «El comercio de granos y la economía de Madrid en los siglos Xvir y xviII", Papeles de Economia Española, 20, pp. 350-360.

De LA Hoz, C. (1985): Fiscalidad y Hacienda Municipal en el Madrid del Antiguo Régi-

De LA Hoz, C. (1985): Fiscalidad y Hacienda Municipal en el
men. Las Sisas (1680-1808) (tesis de licenciatura), Universidad Autónoma de Madrid.
Hernando, J. (1985): Los Bienes de Propios de Madrid en el siglo XVIII (tesis de licenciatura) $)_{Y}$ Universidad Autónoma de Madrid.

Hibbert, A. B. (1953): «Medieval Town Patricians», Past and Present, 3, pp. 15-27.

Merrington, J. (1977): «Ciudad y Campo en la Transición al Capitalismo sición del Feudalismo al Capitalismo, Barcelona, Cañola 1560.1850, Madrid, Alianza.

RINGRoSE, D. (1985): Madrid y la economionacional, Barcelona, Crítica.

SERENI, E. (1980): Capitalismo y mercado nacional, Ban's Importance in changing English WRIGLEY, E. A. (1967): «A Simple Model of London'st 37, pp. 44-70.
Society and Economy, 1650-1750, Past and Present, 